\title{
VLA-4 Integrin Can Mediate CD11/CD18-independent Transendothelial Migration of Human Monocytes
}

\author{
H. Eduardo Chuluyan and Andrew C. Issekutz \\ Departments of Pediatrics and Microbiology-Immunology, Dalhousie University, Halifax, Nova Scotia, Canada, B3J $3 G 9$
}

\begin{abstract}
The migration of human monocytes across unactivated and activated human umbilical vein endothelium (HUVE) in response to chemotactic factors was studied, and the adhesion molecules involved were characterized. Migration of blood monocytes or U937 cell line-derived monocytes across unactivated HUVE induced by C5a, was partially inhibited (by 75\%) by mAbs (R15.7 or 60.3) to CD18 of the CD11/CD18 complex on the monocyte. However, when the HUVE was pretreated for $5 \mathrm{~h}$ with IL-1 $\alpha(0.1 \mathrm{ng} / \mathrm{ml})$, TNF- $\alpha(100 \mathrm{U} / \mathrm{ml})$, or LPS $(1 \mathrm{ng} / \mathrm{ml})$, migration induced by C5a was no longer inhibited; i.e., migration became CD18 independent. The monocyte CD18-independent migration was completely blocked by mAbs against $\alpha_{4}$ or $\beta_{1}$ integrin chains of VLA-4. This migration was also partially inhibited by $\mathrm{mAbs}$ against vascular cell adhesion molecule-1 (VCAM-1), a major counter-receptor on HUVE for VLA-4, but not by $\mathrm{mAbs}$ to $\mathrm{E}$-selectin or intercellular adhesion molecule-1. The significant CD18-independent migration across "unactivated" HUVE was also inhibited by mAbs against $\alpha_{4}$ or $\beta_{1}$ chains of VLA-4, although mAbs against VCAM-1 did not inhibit under these conditions. Finally, considerable VLA-4dependent transendothelial migration to C5a was also observed with monocytes from a patient with CD18 deficiency (leukocyte adhesion deficiency). These results suggest that (a) there is a major CD18-independent component in monocyte chemotactic factor-dependent migration across activated and unactivated endothelium; (b) that VLA-4 integrin on the monocyte has a major role in this migration; and (c) that VCAM-1 on activated endothelium functions as a counter-receptor in this process, but other ligands for VLA-4, especially on unactivated endothelium, may also be involved. (J. Clin. Invest. 1993. 92:27682777.) Key words: inflammation • chemotaxis • leukocyte • endothelium
\end{abstract}

\section{Introduction}

The movement of monocytes and polymorphonuclear leukocytes (PMNL) ${ }^{1}$ from blood into tissues is a characteristic fea-

Address correspondence to Dr. Andrew C. Issekutz, Department of Pediatrics, Izaak Walton Killam Children's Hospital, 5850 University Avenue, Halifax, NS Canada B3J 3G9. 1993.

Received for publication 26 April 1993 and in revised form 27 July

1. Abbreviations used in this paper: HUVE, human umbilical vein endothelium; ICAM-1, intercellular adhesion molecule-1; LAD, leukocyte adhesion deficiency; PMNL, polymorphonuclear leukocytes;

J. Clin. Invest.

(c) The American Society for Clinical Investigation, Inc.

$0021-9738 / 93 / 12 / 2768 / 10 \quad \$ 2.00$

Volume 92, December 1993, 2768-2777 ture of inflammation. At the present time, the mechanisms of monocyte infiltration into inflammatory sites are not fully understood. However, involvement of chemotactic factors produced in the inflamed tissue (1-3) appear to be important in leukocyte emigration from the blood across vascular endothelium. Chemotactic factor-dependent migration involves binding of the factor to specific membrane receptors on PMNL and monocytes and intracellular signal transduction (4). Chemotactic factor-induced migration of PMNLs and monocytes does not require other cell types $(1,2,5)$ but is dependent on the $\beta_{2}$ integrin (CD11/CD18) leukocyte surface molecules because mAbs to these adhesion molecules markedly inhibit migration $(6,7)$. Furthermore, in patients whose leukocytes are congenitally deficient in the CD11/CD18 proteins, their PMNLs fail to migrate across endothelial monolayers in response to chemoattractants $(6,8,9)$. However, the role of CD11/CD18 proteins in chemotactic factor-dependent migration of monocytes is only partial because mAbs against the common $\beta_{2}$ subunit (CD18) only partially ( $\left.\leq 75 \%\right)$ inhibit migration $(10,11)$, suggesting that a CD18-independent mechanism may also be involved in monocyte chemotactic factordependent migration.

Recently, leukocyte migration has been recognized as having an important endothelial cell dependent component. This mechanism involves the activation of endothelial cells by cytokines such as IL- 1, TNF- $\alpha$, or the bacterial product endotoxin (LPS) (3). In this process, endothelial cells undergo profound functional alterations and express adhesion molecules for leukocytes. These stimuli do not induce PMNL migration directly, but we and others have shown that IL-1, TNF- $\alpha$, and LPS activate vascular endothelial cells in vitro to increase PMNL adhesion and transendothelial migration (3, 6, 12-14). This process involves increased surface expression on the endothelial cell of the membrane glycoproteins E-selectin, intercellular adhesion molecule-1 (ICAM-1), and vascular cell adhesion molecule (VCAM-1) $(3,15,16)$. These molecules on the endothelium interact with sialyl Lewis $\mathrm{X}$ containing molecules, the CD1 1/CD18 and the VLA-4 integrins $\left(\alpha_{4} \beta_{1}\right)$, respectively, on leukocytes including monocytes $(3,17-20)$.

For PMNL migration, the interaction of CD11/CD18 with ICAM-1 on activated endothelium appears essential $(6,13)$. However, the adhesion/migration mechanisms involved in monocyte transendothelial migration is less clear. To date, most of the studies with monocytes have focused on their adhesion mechanisms (21-24) or migration stimulated by chemotactic factors $(11,25-27)$. There have been few studies of cytokine-activated endothelial cell-dependent migration. This is, in part, because it has been difficult to demonstrate this mechanism in vitro with monocytes because of a weaker migration response and a higher unstimulated background response than

VCAM-1, vascular cell adhesion molecule-1; ZAP, zymosan-activated plasma. 
with PMNL $(10,28)$. However, in vivo studies clearly show that monocyte infiltration and migration occur rapidly at tissue sites injected with endothelium-activating cytokines such as IL-1, TNF- $\alpha$, or LPS (29-31). One reason for such discrepancy could be that in vivo, both endothelial cell-dependent and monocyte chemotactic factor-dependent mechanisms may be simultaneously operative, since IL- 1 , TNF- $\alpha$, and LPS are now known to induce the synthesis by connective tissue cells of chemotactic factors for leukocytes, including monocytes $(32,33)$. Furthermore, it is increasingly recognized that inflamed tissues and exudate fluids contain pathophysiologically relevant concentrations of monocyte chemotactic factors (e.g., C5a, leukotriene B4, and monocyte chemotactic protein1 in conjunction with IL- 1 and $\operatorname{TNF}(2,32,34,35)$. In such tissues, the local vascular endothelium expresses leukocyte adhesion molecules, suggesting activation by the latter cytokines $(29,36,37)$. Therefore, to model this complex in vivo situation, we investigated monocyte migration in vitro in response to chemotactic factors across both resting and IL-1-, TNF- $\alpha-$, or LPS-activated HUVE. Under these migration conditions, we studied the monocyte and endothelium adhesion molecules required for monocyte migration. Our results indicate that chemotactic factors induce marked migration of monocytes across resting and activated endothelium. Furthermore, in the presence of an activated endothelium, the CD11/CD18 complex is not required for migration, but rather, the VLA-4 integrin can function as an alternative mechanism for the migration of monocytes.

\section{Methods}

Monoclonal antibodies. A number of function-blocking mAbs were generously provided for these studies. These included mAbs 60.3 ( $\mathrm{IgG}_{2 \mathrm{a}}$ from Dr. J. M. Harlan, University of Washington, Seattle, WA) (38), R15.7 ( $\mathrm{IgG}_{1}$ from Dr. R. Rothlein, Boehringer Ingelheim, Ridgefield, CT) (39), and TS1/18 (IgG from Dr. T. A. Springer, Harvard University, Boston, MA) (40), which are known to block CD18 adhesion functions. Other $\mathrm{mAbs}$ reactive with monocytes were DREG200 ( $\mathrm{IgG}_{1}$ from Dr. C. W. Smith, Baylor University, Dallas, TX), which blocks L-selectin (41), HP1/2 (IgG from Dr. R. Lobb, Biogen Inc., Cambridge, MA) against $\alpha_{4}(42)$ and Ab13 (rat IgG 1 from Dr. K. Yamada, National Institute of Health, Bethesda, MD) against the $\beta_{1}$ integrin chains (43). The mAb CSLEX against sialyl Lewis $X$ blood group, W6/32 against HLA-Class I framework, 3C10 against CD14 and 543 against CR 1 were all obtained from the American Type Culture Collection (Rockville, MD). The following mAbs reactive with HUVE were used: $\mathrm{mAb} 2 \mathrm{G} 7\left(\mathrm{IgG}_{1} \text { as F[ab }\right]_{2}$ ) from Dr. W. Newman (Otsuka Amer-

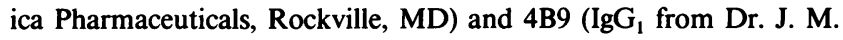
Harlan) both against VCAM-1 $(16,44)$, mAbs $5 D 10\left(\operatorname{IgG}_{2 \mathrm{a}}\right.$ as $\mathrm{F}[\mathrm{ab}]_{2}$ from Dr. W. Newman) and $84 \mathrm{H} 10$ ( $\mathrm{IgG}_{1}$; AMAC Inc., Westbrook, ME) both against human ICAM-1 (45) and mAb BB11 ( IgG $_{2 b}$ from Dr. R. Lobb) against E-selectin (46). These block adhesion function epitopes on their respective antigens. Purified $\operatorname{IgG}$ or $F(a b)_{2}$ fragments were used as indicated at at least twofold saturating concentrations as assessed by immunofluorescence or ELISA.

Reagents. Recombinant human IL- $1 \alpha$, which had a specific activity of $4 \times 10^{7} \mathrm{U} / \mathrm{mg}$, was a gift from Dr. D. Urdal (Immunex Corp., Seattle, WA). Recombinant human TNF- $\alpha$ (specific activity $=5 \times 10^{7}$ $\mathrm{U} / \mathrm{mg}$ ) and IFN- $\tau\left(10^{7} \mathrm{U} / \mathrm{mg}\right)$ were gifts from Genentech Inc. (South San Francisco, CA). All of these cytokines contained $\leq 1 \mathrm{ng}$ of LPS $/ \mathrm{mg}$. Each of the cytokines were diluted immediately before use in $0.1 \%$ LPS-free HSA (Connaught Laboratories, Don Mills, Ontario, Canada) in PBS. Escherichia coli 0111 LPS was from List Biologicals (Campbell, CA). Recombinant human C5a was a gift from CIBA-Geigy Pharmaceuticals (Summit, NJ).
Monocyte isolation from normal donors and a patient with CD18 deficiency. Sterile plasticware and pyrogen-free water (Travenol, Malton, Ontario, Canada) and solutions were used throughout. Venous blood from healthy human volunteers and from a patient with leukocyte adhesion deficiency (LAD) was collected into EDTA $(0.1 \%)$ plus acid citrate dextrose $(0.8 \mathrm{ml} / 10 \mathrm{ml}$ of blood, acid citrate dextrose formula A; Travenol) anticoagulant. The LAD patient has previously been reported (47). He has severe CD1 8 deficiency with $<4 \%$ of normal expression of the CD11/CD18 molecular complex on leukocytes. The blood sample from this boy was collected by Dr. Zave Chad (Hôpital Ste. Justine, Montreal, PQ), along with a sample from a control, and couriered overnight to our laboratory for study. The red cells in the blood samples were separated by sedimentation with $6 \%$ dextran saline solution (Travenol) (1 part to 5 of blood) and the leukocyte-rich plasma was harvested. The leukocytes were sedimented $(150 \mathrm{~g} \times 10$ min at $22^{\circ} \mathrm{C}$ ), the pellet was resuspended in $\mathrm{Ca}^{++}, \mathrm{Mg}^{++}$-free Tyrode's solution with $5 \%$ autologous platelet-poor plasma, and labeled with ${ }^{51} \mathrm{Cr}$ sodium chromate $(25 \mu \mathrm{Ci} / \mathrm{ml})$ (Amersham Corp., Oakville, Ontario, Canada) by incubation for $30 \mathrm{~min}$ at $37^{\circ} \mathrm{C}$. During this incubation, the osmolarity of the medium was gradually increased in three steps from 290 to 360 mosmol by addition of $9 \% \mathrm{NaCl}$, as previously described by Boyum (48) and Recalde (49). This improved the monocyte purity and did not affect cell viability or function as reported previously $(48,49)$. After the incubation period, labeled leukocytes were washed once with $\mathrm{Ca}^{++}, \mathrm{Mg}^{++}$-free Tyrode's solution (360 mos$\mathrm{mol}), 5 \% \mathrm{PPP}$, and resuspended in hyperosmotic $(360 \mathrm{mosmol}) \mathrm{Ca}^{++}$, $\mathrm{Mg}^{++}$-free Tyrode's solution containing $0.2 \%$ EDTA and $10 \%$ plateletpoor plasma-Percoll (Pharmacia Fine Chemicals, Dorval, PQ) to achieve 56\% Percoll concentration (based on $100 \%=$ isotonic Percoll). Six different Percoll cushions of $2.5 \mathrm{ml}$ each were layered in a $15-\mathrm{ml}$ conical polypropylene tube with $73 \%$ Percoll at the bottom followed by $62 \%, 56 \%$ (containing the labeled leukocytes), $50 \%, 46 \%$, and $40 \%$. Density gradient centrifugation was at $400 \mathrm{~g}\left(25 \mathrm{~min}\right.$ at $\left.22^{\circ} \mathrm{C}\right)$ in a swinging bucket rotor. Six bands were resolved, harvested, and washed twice with isotonic $\mathrm{Ca}^{++}, \mathrm{Mg}^{++}$-free Tyrode's solution-0.1\% HSA (LPS free). The purest monocyte fraction was recovered at the $46-40 \%$ Percoll interphase yielding 3-4 $\times 10^{6}$ monocytes from $40 \mathrm{ml}$ of starting blood with $>90 \%$ purity, $>95 \%$ viability by neutral red staining and trypan blue exclusion, and minimal platelet contamination. Platelets were found to band above the $40 \%$ Percoll cushion. Monocytes were identified by neutral red and nonspecific esterase staining (50), glass adherence and spreading and immunofluorescence staining of $\geq 90 \%$ of the cells, with mAbs $63 \mathrm{D} 3$ or $3 \mathrm{C} 10$ to $\mathrm{CD} 14$ and mAb OKM1 to Mac-1. The monocyte preparation contained $<3 \%$ contaminating $\mathrm{CD} 2, \mathrm{CD} 3$, or $\mathrm{CD} 20$ positive cells and there were no neutrophils, eosinophils, or basophils in the monocyte fraction. The monocytes were resuspended at a final concentration of $7 \times 10^{5} / \mathrm{ml}$ in RPMI $1640,0.5 \%$ HSA containing $10 \mathrm{mM}$ Hepes ( $\mathrm{pH}$ 7.4) for migration studies.

Preparation of U937 cell line. The U937 cell line was obtained from the American Type Culture Collection and cultured $\left(37^{\circ} \mathrm{C}-5 \% \mathrm{CO}_{2}\right)$ in suspension between $0.2 \times 10^{6}$ and $1 \times 10^{6}$ cells $/ \mathrm{ml}$ in RPMI 1640 medium-10\% FCS. Differentiation of these cells was induced by addition of dibutyryl cAMP $\left(10^{-3} \mathrm{M}\right)$ at a cell density of $0.3 \times 10^{6}$ cells $/ \mathrm{ml}$. Most studies were carried out on U937 cells after 48-72 h of exposure to dibutyryl cAMP, since expression of C5a receptors and the chemotactic response was fully developed at this time (51). The differentiated cells were ${ }^{51} \mathrm{Cr}$-labeled, washed, and resuspended at $1 \times 10^{6} / \mathrm{ml}$ in RPMI 1640, 0.5\% HSA, $10 \mathrm{mM}$ Hepes for migration assays.

Endothelial cell cultures. Human umbilical vein endothelial cells were isolated and cultured in flasks as described by Jaffe et al. (52), and cultured on filters as previously described by us (12). Briefly, endothelial cells were isolated from umbilical cords after treatment with 0.5 $\mathrm{mg} / \mathrm{ml}$ collagenase (Cooper Biomedical, Mississagua, Ontario, Canada), in 0.01 M PBS, pH 7.4, and grown in RPMI 1640 (ICN, Mississagua, Ontario, Canada) containing $2 \mathrm{mM}$ L-glutamine, 2-mercaptoethanol, sodium pyruvate, penicillin G/streptomycin (Gibco Laboratories, Grand Island, NY) and supplemented with 20\% FCS (Hyclone Laboratories, Logan, UT), $25 \mu \mathrm{g} / \mathrm{ml}$ endothelial cell growth supple- 
ment (Collaborative Research, Lexington, MA), and heparin (45 $\mu \mathrm{g}$ / $\mathrm{ml}$ ) (Sigma Chemical Co., St. Louis, MO). This is referred to as growth medium. Cells were cultured in gelatin-coated culture flasks (Nunc; Gibco Laboratories). The HUVE were detached using $0.025 \%$ trypsin/ $0.01 \%$ Versene (MA Bioproducts, Walkerville, MD) and cultured on PVP-free polycarbonate filters bearing $5 \mu \mathrm{m}$ pores in $65-\mathrm{mm}$ di culture plate inserts (Transwell 3415; Costar Corp., Cambridge, MA). The filters were first prepared by coating with $0.01 \%$ gelatin $\left(37^{\circ} \mathrm{C}, 18 \mathrm{~h}\right)$ followed by application of $3 \mu \mathrm{g}$ in $50 \mu \mathrm{l}$ water of human fibronectin (Collaborative Research) at $37^{\circ} \mathrm{C}$ for $2 \mathrm{~h}$. Fibronectin was then replaced by HUVE $\left(2 \times 10^{4}\right.$ cells $)$ from the first or second passage, added above the filter in $0.1 \mathrm{ml}$ growth medium, and $0.6 \mathrm{ml}$ growth medium was added to the lower compartment beneath the filter. The HUVE formed a tight permeability barrier in 5-6 d, and were evaluated for confluence before use by ${ }^{125} \mathrm{I}-\mathrm{HSA}$ diffusion as previously described (12).

Monocyte and U937 cell transendothelial migration. For migration assays, HUVE monolayers on the filters and the lower compartment beneath the filters were washed with RPMI 1640 and stimulated for $5 \mathrm{~h}$ by addition of IL- $1 \alpha$, TNF- $\alpha$, or LPS to the lower compartment in fresh RPMI 1640 with $10 \%$ FCS. When IFN- $\tau$ was used as stimulus, the cytokine was added to the lower compartment 5 or $20 \mathrm{~h}$ before the migration assay. After incubation with cytokines, the upper and lower surfaces of the HUVE filter units were washed with RPMI 1640, and then they were transferred to a new, clean well (lower compartment). To this well, $0.6 \mathrm{ml}$ of RPMI-1640, $10 \mathrm{mM}$ Hepes, $0.5 \%$ HSA was added containing the chemotactic stimulus (C5a or FNLP; Sigma Chemical Co.). Before immersion of the HUVE filter unit, $0.1 \mathrm{ml}$ of medium containing $7 \times 10^{4}{ }^{51} \mathrm{Cr}$ monocytes or $10^{5}{ }^{51} \mathrm{Cr}$ U937 were added above the HUVE. After incubation (usually $90 \mathrm{~min}$ ), migration was stopped by washing of the upper compartment twice with $0.1 \mathrm{ml}$ RPMI 1640 to remove nonadherent monocytes or U937. The undersurface of the filter was then vigorously rinsed with $2 \mathrm{ml}$ of ice-cold PBS/0.2\% EDTA solution and collected into the lower compartment. The HUVE filter unit (upper compartment) was then placed into 0.7 $\mathrm{ml}$ of $0.5 \mathrm{M} \mathrm{NaOH}$ to allow dissolution of adhered monocytes. The cells that migrated into the lower compartment or were detached from the undersurface of the filters by the cold PBS/EDTA were lysed by addition of $0.5 \%$ Triton $\mathrm{X}-100$. The $\mathrm{NaOH}$ solution bathing the filters (adherent cells) and the contents of the lower chamber (migrated cells) were analyzed for ${ }^{51} \mathrm{Cr}$ and results are expressed as the percentage of the total ${ }^{51} \mathrm{Cr}$-monocytes or U937 added above the HUVE, which were recovered in each fraction. All the stimulation conditions were performed with triplicate replicates.

Monoclonal antibody treatments. In some experiments, ${ }^{51} \mathrm{Cr}$-monocytes or ${ }^{51} \mathrm{Cr}$-U937 were treated for $20 \mathrm{~min}$ at room temperature with the mAbs indicated at saturating concentrations $(20-40 \mu \mathrm{g} / \mathrm{ml})$ as determined by immunofluorescence flow cytometry, and then tested for migration in the presence of the antibody. In some experiments, the HUVE was treated for $40 \mathrm{~min}$ at $37^{\circ} \mathrm{C}$ with saturating concentrations of mAbs as determined by ELISA, followed by the addition of the ${ }^{51} \mathrm{Cr}$ labeled monocytes or U937 cells.

Statistical analysis. Student's $t$ test and ANOVA were used for statistical analysis of the data, with individual group means compared using post hoc Bonferroni analysis. $P>0.05$ was not considered significant.

\section{Results}

Chemotactic factor-dependent monocyte migration. The optimal conditions for monocyte migration across HUVE monolayers was determined by performing dose response and time course experiments with the chemotactic factor, C5a. Fig. $1 a$ shows that all C5a concentrations tested significantly increased monocyte migration above control levels with $5 \times 10^{-10} \mathrm{M}$ inducing the maximal monocyte response. The transendothelial migration of monocytes in response to C5a as a function of time is shown in Fig. 1 b. Migration was detectable within 30 min and plateaued by $90-120 \mathrm{~min}$. By this time, $\sim 54 \%$ of the added monocytes placed in the upper chamber had traversed the endothelial monolayer and supporting filter. 90 min was the time chosen for the monocyte migration studies subsequently.

Endothelial cell dependent IL-1 $\alpha$-induced monocyte migration. In the case of PMNL, activation of the HUVE by IL-1 or TNF- $\alpha$ induces strong PMNL adhesion and marked transendothelial migration (25-35\% of added PMNL) in this assay system as shown by us previously (12). As shown in Fig. $2 a$, IL- $1 \alpha$ stimulation of the HUVE caused only a small amount (6.4\%) of monocyte transendothelial migration but this was significantly greater than across unstimulated HUVE. This was associated with a more marked increase in monocyte adhesion (Fig. $2 b$ ). Neither an increase in the IL- $1 \alpha$ concentration in the duration of stimulation with IL- $1 \alpha \leq 24 \mathrm{~h}$ or in the migration time enhanced the IL-1-induced monocyte migration (not shown). A small increase in monocyte migration and more marked adhesion was observed also when TNF- $\alpha$ or LPS were used to activate the HUVE as shown in Fig. 2. In contrast, IFN- $\gamma$ stimulation of the HUVE had no effect on monocyte migration or adhesion.

Requirement for CD18 in chemotactic factor-and endothelium-dependent monocyte migration. We next examined the role of CD11/CD18 on monocytes in transendothelial migration. Fig. 3 shows that mAbs against the common CD18 $\beta_{2}$ integrin chain $(60.3, \mathrm{R} 15.7$, or TS1/18), but not control $\mathrm{mAb}$ (e.g., against CD14 [3C10] or CR1 [mAb543] [not shown])

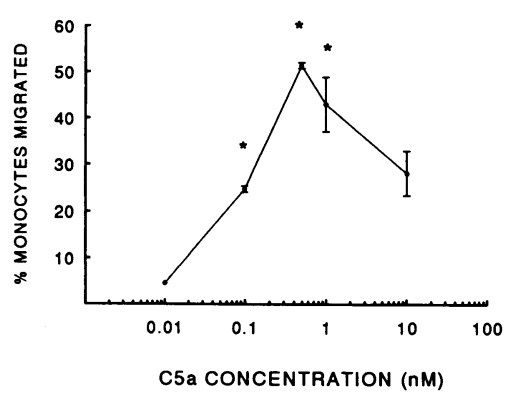

b

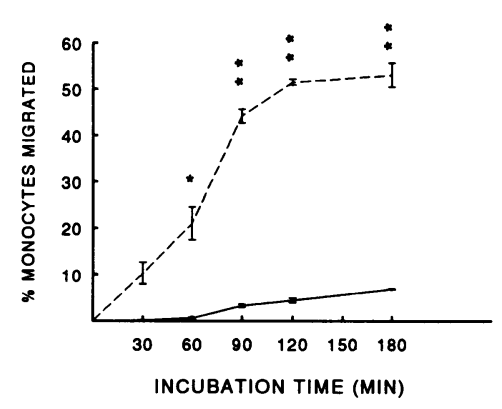

Figure 1. Dose response curve and time course of human monocyte transendothelial migration induced by C5a. (a) Labeled ${ }^{51} \mathrm{Cr}$-monocytes $\left(7 \times 10^{4}\right)$ were added above the HUVE monolayer and stimulated with varying concentrations of recombinant $\mathrm{C5a}$ added beneath the monolayer/filter unit to induce migration across the HUVE monolayer as described in the Methods. (b) Migration was induced with $5 \times$ $10^{-10}$ M C5a (---) or no stimulus (-) and stopped after various incubation times. Results are expressed as the percent of added monocytes that migrated through the HUVE filter unit. The data shown are taken from one representative experiment of two similar experiments. Each point represents the mean value for triplicate wells, \pm SD. ${ }^{*} P<0.05,{ }^{* *} P<0.01$; post hoc Bonferroni analysis. 
a

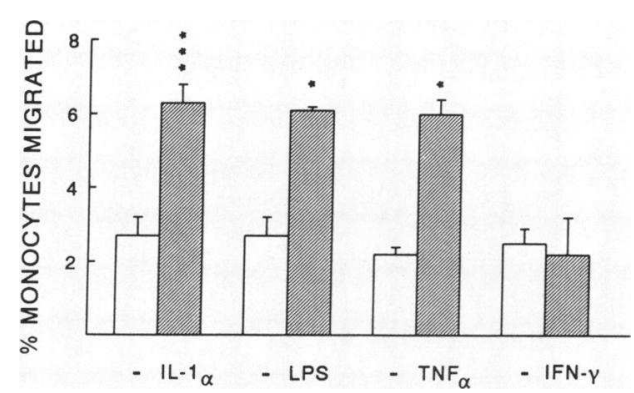

b

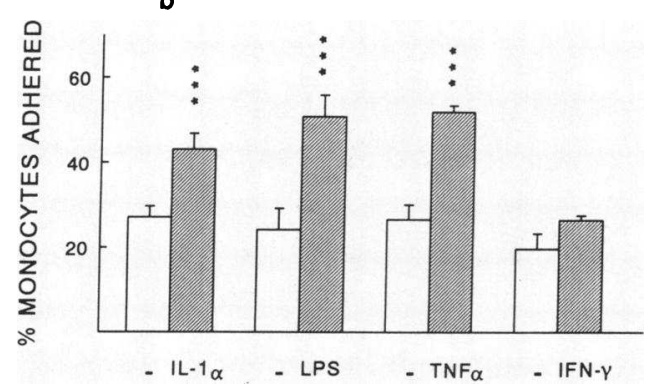

Figure 2. Effect of IL-1 $\alpha$, LPS, TNF- $\alpha$, and IFN- $\tau$ on monocyte migration $(a)$ and adhesion $(b)$ through endothelium. Human umbilical vein endothelial monolayers were grown on polycarbonate filters and were unstimulated or stimulated for $5 \mathrm{~h}$ with IL- $1 \alpha(0.1 \mathrm{ng} / \mathrm{ml}), \mathrm{LPS}$ $(1 \mathrm{ng} / \mathrm{ml})$, TNF- $\alpha(100 \mathrm{U} / \mathrm{ml})$, or for $\leq 20 \mathrm{~h}$ with IFN- $\tau(200 \mathrm{U} / \mathrm{ml})$. Medium was then exchanged and ${ }^{51} \mathrm{Cr}$-labeled monocytes were added above the monolayers and incubated for $90 \mathrm{~min}$ as described in Methods. Results are expressed as the percent of added monocytes that migrated through the HUVE filter unit $(a)$ or remained adherent (b) to the HUVE. Values represent the mean \pm SEM of 16 separate experiments for IL- $1 \alpha$ and three experiments with the other agents, performed in triplicate. ${ }^{*} P<0.05 ;{ }^{* * *} P<0.001$; Student's paired $t$ test.

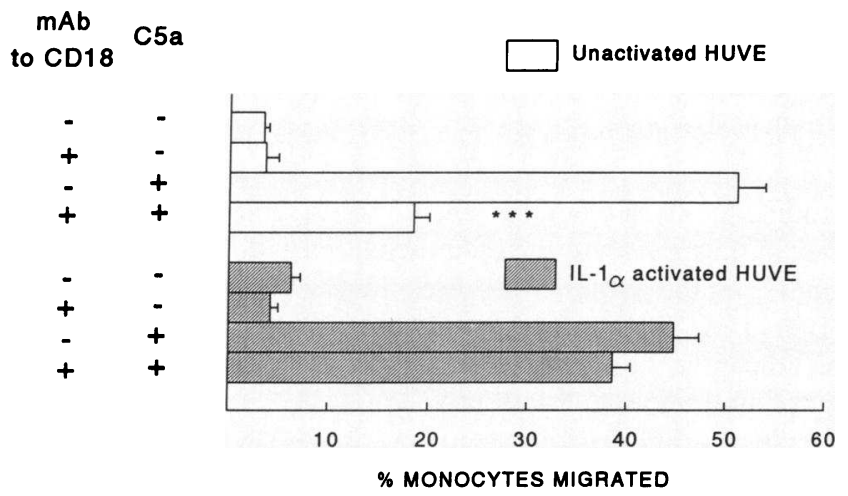

Figure 3. Effect of mAb against CD18 on C5a and IL- $1 \alpha$-induced monocyte transendothelial migration. HUVE monolayers were incubated with medium alone or IL- $1 \alpha(0.1 \mathrm{ng} / \mathrm{ml})$ for $5 \mathrm{~h}$, after which time, medium was exchanged and ${ }^{51} \mathrm{Cr}$-monocytes were added. The monocytes were incubated with saturating amounts $(20-40 \mu \mathrm{g} / \mathrm{ml})$ of control mAbs (3C10 or 543) or mAbs to CD18 (i.e., R15.7, or 60.3 or TS1/18) (results were pooled) for $20 \mathrm{~min}$ at room temperature, and then added above the activated or unactivated HUVE. C5a (5 $\times 10^{-10} \mathrm{M}$ ) was added beneath the HUVE/filter unit. Data are expressed as in Fig. 1 and represent the mean \pm SEM of more than 16 experiments performed with triplicate wells. ${ }^{* * *} P<0.001$ compared with control mAb-treated group + C5a, or C5a + IL- $1 \alpha+$ antiCD18-treated group, using post hoc Bonferroni analysis. partially inhibited (i.e., by $70 \%$ ) C5a-induced monocyte transendothelial migration. It is important to point out that these mAbs to CD18 inhibited PMNL transendothelial migration to $\mathrm{C} 5 \mathrm{a}$ in the same assay system by $>90 \%$ in agreement with published reports $(6,7)$ (data not shown). These results suggest the presence of a CD18-independent mechanism involved in monocyte chemotactic factor-dependent migration.

The shaded bars in Fig. 3 show that the same mAbs to CD18 did not inhibit monocyte migration induced by C5a through an IL-1-activated endothelium. This lack of inhibition was not dependent on the chemotactic factor tested, since migration induced by FNLP across IL- $1 \alpha$-activated HUVE was also unaffected by mAbs to CD18 (FNLP $3 \times 10^{-9} \mathrm{M}$ + IL- $1 \alpha$-activated HUVE $=20.2 \pm 1.4 \%$; FNLP + IL- $1 \alpha-$ activated HUVE $+\mathrm{mAb}$ to $\mathrm{CD} 18=21.1 \pm 0.2 \%$ migrated). Fig. 4 shows that TNF- $\alpha$ and LPS activation of the HUVE $(5 \mathrm{~h}$ pretreatment) also resulted in monocyte transendothelial migration to C5a, which was CD18 independent, since the mAbs to $\mathrm{CD} 18$ did not inhibit this migration. In contrast, IFN- $\tau$ treatment $(5$ or $20 \mathrm{~h})$ did not modify the inhibition observed with mAbs to CD18, suggesting that IFN- $\tau$ is not able to upregulate on the HUVE, the mechanisms or adhesion molecules involved in CD18-independent monocyte migration. It should be pointed out that the concentration $(200 \mathrm{U} / \mathrm{ml})$ and the lot of IFN- $\gamma$ used in these experiments was shown by us recently to upregulate ICAM- 1 and potentiate LPS-induced PMNL transendothelial migration (53).

To determine whether the CD18-independent monocyte migration might have been caused by the isolation procedure used or whether it might have selected for a subpopulation of monocytes, we also examined the migration of U937 cells, which is a monocyte-like cell line. After treatment of the U937 cells with dibutyryl cyclic AMP for 48-72 $\mathrm{h}$, they acquired the capacity to migrate in response to $\mathrm{C} 5 \mathrm{a}$, as described previously by Gavison et al. (51). Fig. 5 shows that mAbs against CD18 partially inhibited the migration of U937 cells to zymosan-activated plasma (ZAP), the active component of which is $\mathrm{C} 5 \mathrm{a}$ des $\operatorname{Arg}(54)$. However, like with blood monocytes, the mAb to

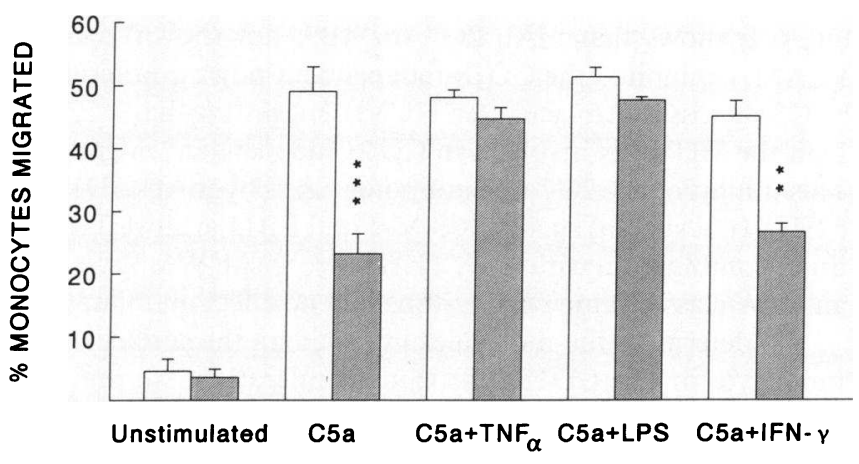

Figure 4. Effect of mAb against CD18 on C5a induced monocyte migration across TNF- $\alpha$, LPS, or IFN- $\tau$ activated endothelium. Labeled ${ }^{51} \mathrm{Cr}$-monocytes $\left(7 \times 10^{4}\right)$ treated with control mAb 543 (antiCR1) or 3C10 (anti-CD14) (open bars) or treated with mAb R15.7 against $\mathrm{CD} 18$ (hatched bars), were tested for $\mathrm{C} 5 \mathrm{a}\left(5 \times 10^{-10} \mathrm{M}\right)$ induced transendothelial migration through unactivated HUVE or HUVE activated with TNF- $\alpha(100 \mathrm{U} / \mathrm{ml}, 5 \mathrm{~h}), \mathrm{LPS}(1 \mathrm{ng} / \mathrm{ml}, 5 \mathrm{~h})$ or IFN- $\tau(200 \mathrm{U} / \mathrm{ml}, 20 \mathrm{~h})$. Data are expressed as the percent of added monocytes that migrated and represent the mean \pm SEM of three or more experiments performed in triplicate. ${ }^{* * *} P<0.001,{ }^{* *} P<0.01$ compared with $\mathrm{C} 5 \mathrm{a}$ treated group, using post hoc Bonferroni analysis. 


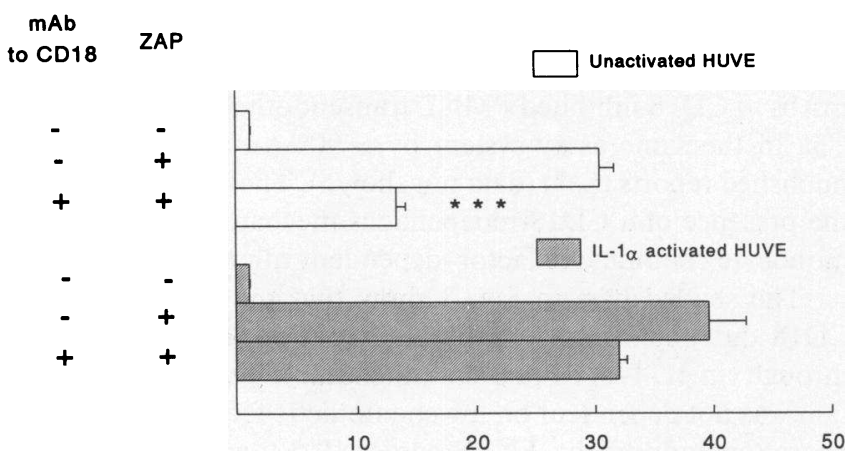

\% U937 CELLS MIGRATED

Figure 5. Effect of mAb against CD18 on C5a- and IL- $1 \alpha$-induced transendothelial migration of U937 cells. HUVE monolayers were incubated with medium alone or HUVE activated with IL- $1 \alpha(0.1$ $\mathrm{ng} / \mathrm{ml}$ ) for $5 \mathrm{~h}$, after which time medium was exchanged and ${ }^{51} \mathrm{Cr}$-labeled $\mathrm{U} 937$ cells $\left(10^{5}\right)$ treated $(20 \mathrm{~min}$ at room temperature) with saturating amounts $(20-40 \mu \mathrm{g} / \mathrm{ml})$ of control mAb to CD14 (3C10) or mAbs to CD18 (R15.7 or 60.3 ) were added above activated or unactivated HUVE. Migration was induced by C5a-containing zymosan-activated plasma (ZAP 1\%). Data shown are taken from one representative experiment of three similar experiments. Each point represents the mean value for triplicate wells, \pm SD. ${ }^{* * *} P<0.001$ compared with the unactivated group with ZAP alone or IL- $1 \alpha$-activated HUVE + ZAP + mAb to CD18; post hoc Bonferroni analysis.

CD18 failed to inhibit the migration when the HUVE was previously activated by IL-1.

Molecules involved in CD18-independent monocyte migration across IL-1 $\alpha$-activated endothelium. We investigated the mechanisms that may contribute to CD18-independent migration by using $\mathrm{mAbs}$ directed against adhesion molecules on the surface of monocytes and on endothelial cells. The participation of E-selectin, ICAM-1, and VCAM-1 was assessed by incubating IL- $1 \alpha$-treated HUVE with specific blocking mAbs against E-selectin, ICAM-1, or VCAM-1, and quantitating the C5a-induced migration of monocytes, which were treated with $\mathrm{mAb}$ to $\mathrm{CD} 18$. All of the mAbs were present during the assay. Fig. $6 a$ shows that mAb $2 \mathrm{G} 7$ (or 4B9, not shown) against VCAM-1 inhibited the CD18-independent migration induced by C5a across IL- $1 \alpha$-activated HUVE, suggesting that VCAM1 on the HUVE is involved in CD18-independent migration. This inhibition by $2 \mathrm{G} 7$ was not potentiated by mAbs $5 \mathrm{D} 10$ or 84H10 (not shown) against ICAM-1 and BB1 1 against E-selectin in combination with $2 \mathrm{G} 7$. The control $\mathrm{mAb} \mathrm{W6/32}$ against an HLA-class I framework epitope had no effect on migration.

To determine the molecules involved on the surface of the monocyte in this CD18-independent migration, we preincubated the monocytes with $\mathrm{mAb}$ to $\mathrm{CD} 18$ plus blocking mAb HP1/2 to the $\alpha_{4}$ integrin chain of VLA- 4 or mAb13 to $\beta_{1}$ integrin, or mAb DREG200 to L-selectin or MAb CSLEX to the sialyl LewX carbohydrate. Fig. $6 b$ shows that of these, only the mAb against $\alpha_{4}(\mathrm{HP} 1 / 2)$ or against $\beta_{1}$ integrin (mAb13) inhibited the CD18-independent migration. It is important to point out that the inhibition is almost complete by mAb HP1/2, as well as by mAb13, suggesting that VLA-4 on the monocyte is a major CD18-independent migration mechanism.

Molecules involved in CD18-independent migration across unactivated endothelium. The adhesion molecules involved in CD18-independent migration across unactivated HUVE were

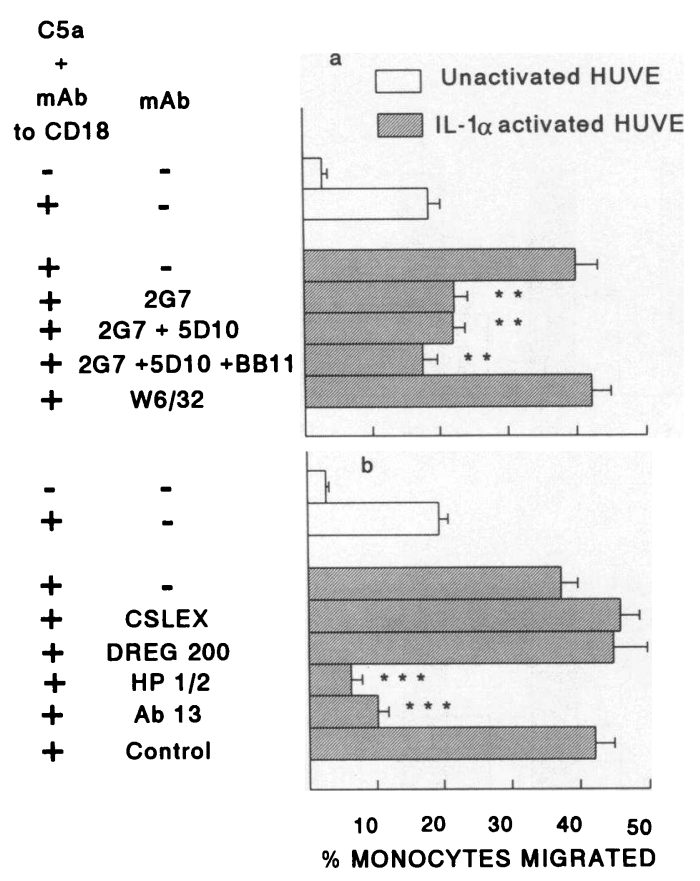

Figure 6. Effect of mAbs against endothelial cell and monocyte adhesion molecules on monocyte CD18-independent migration through IL- $1 \alpha$-activated HUVE in response to C5a. (a) IL- $1 \alpha$-activated HUVE was treated with saturating amounts of $\mathrm{mAb} 2 \mathrm{G} 7$ (F[ab'] $]_{2}$; anti-VCAM-1), BB11 (anti-E-selectin), 5D10 (F[ab'] $]_{2}$; anti-ICAM-1), or control mAb W6/32 (F[ab'] $]_{2}$; anti-HLA Class I) for 40 min at $37^{\circ} \mathrm{C}$. Then ${ }^{51} \mathrm{Cr}$ monocytes, which were treated with mAb R15.7 or 60.3 (results were pooled) to CD18 as in Fig. 3, were added above the monolayer, and all the mAbs were present throughout the migration phase. (b) Labeled monocytes were incubated with saturating amounts of mAb to CD18 plus mAb CSLEX (anti-sLex) or DREG200 (anti-L-selectin) or HP1/2 (anti- $\left.\alpha_{4}\right)$ or mAb13 (anti- $\beta_{1}$ integrin) or control mAbs (3C10, anti-CD14; 543, anti-CR-1, results pooled) for $20 \mathrm{~min}$ at room temperature, and then added above the activated HUVE. Data are expressed as the percent of added monocytes migrated and represent the mean \pm SEM of six separate experiments performed with triplicates ${ }^{* * *} P<0.001,{ }^{* *} P<0.01$, compared with C5a + IL-1 + CD18 mAb-treated group, using post hoc Bonferroni analysis.

studied by using blocking mAbs against molecules on the surface of the monocyte and endothelial cell as above. As shown in Fig. $7 a$, the same mAbs used in Fig. 6 against E-selectin (BB11), ICAM-1 (5D10), or VCAM-1 (2G7) did not inhibit significantly the remaining C5a-induced migration of monocytes after treatment with $\mathrm{mAb}$ to CD18 (i.e., the CD18-independent component) across unactivated HUVE. This CD18-independent migration was $\sim 30 \%$ of maximal as shown above in Fig. 3 (open bars). Even when these mAbs were used in combination, the migration on unactivated HUVE was not significantly inhibited.

The participation of VLA-4 in CD18-independent migration on unactivated HUVE was confirmed by preincubating the cells with the blocking mAb HP1/2, Ab13, DREG200, or CSLEX as also performed in Fig. 6. Fig. $7 b$ shows that mAb against $\alpha_{4}$, i.e. HP1/2 or against $\beta_{1}$ integrin (mAb13), inhibited the CD18-independent migration across unactivated HUVE, suggesting that VLA-4 is involved in CD18-independent migration across unactivated HUVE, as well as across IL- $1 \alpha-$ activated HUVE (Fig. 6 b). 


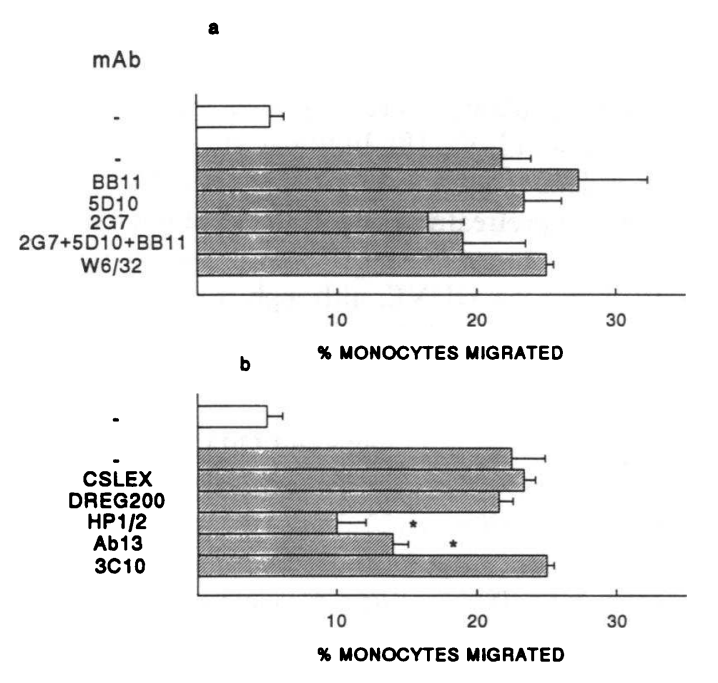

Figure 7. Effect of mAbs against endothelial cell and monocyte adhesion molecules on monocyte CD18-independent migration through unactivated HUVE. (a) Unactivated HUVE was treated with saturating amounts of the designated $\mathrm{mAbs}$ for $40 \mathrm{~min}$ at $37^{\circ} \mathrm{C}$ as in Fig. $6(a)$, after which labeled $\mathrm{CD} 18 \mathrm{mAb}(\mathrm{R} 15.7)$-treated ${ }^{51} \mathrm{Cr}$ monocytes (hatched bars) were added above the monolayer, and C5a was added to the lower compartment. (b) Labeled monocytes were incubated with mAbs to CD18 plus mAbs to sLex (CSLEX), L-selectin (DREG $200), \alpha_{4}(H P 1 / 2)$, or $\beta_{1}(A b 13)$ integrins as in Fig. $6(b)$ at room temperature, and then added above HUVE. Data are expressed as the percent of added monocytes migrated and represent the mean \pm SEM of four separate experiments, each performed with triplicate replicates. ${ }^{*} P<0.05$ compared with $\mathrm{C} 5 \mathrm{a}+\mathrm{CD} 18 \mathrm{mAb}$-treated group, using post hoc Bonferroni analysis.

Role of VLA-4 in C5a-induced monocyte migration across unactivated or IL-1 $\alpha$-activated HUVE. To more clearly determine the role of VLA-4 in C5a-induced monocyte migration through unactivated or IL- $1 \alpha$-activated HUVE, labeled ${ }^{51} \mathrm{Cr}$ monocytes treated with mAb HP1/2 to $\alpha_{4}$ chain of VLA-4 or mAb 60.3 to $\mathrm{CD} 18$ were tested for migration. Fig. $8 a$ shows that $\mathrm{HP} 1 / 2$ alone caused a slight but not statistically significant decrease in C5a-induced migration across unactivated HUVE. The mAb against CD18 caused a 70\% inhibition. Both mAbs together blocked migration almost completely $(>90 \%$ inhibition). However, when the HUVE was activated by IL- $1 \alpha$, neither $\mathrm{mAb}$ alone inhibited the C5a-induced migration. However, when used in combination, there was almost a total inhibition; i.e. to near unstimulated migration in the absence of $\mathrm{C} 5 \mathrm{a}$.

Migration of CD11/CD18-deficient monocytes. We had the opportunity to perform one experiment with monocytes from a patient reported previously (47) to have congenital LAD with nearly complete CD18 deficiency ( $<4 \%$ of normal). Table I shows that the LAD patient's monocytes were impaired in migration to C5a across unactivated HUVE, although they did show some response. However, migration to $\mathrm{C} 5 \mathrm{a}$ increased markedly from $5.9 \%$ on unactivated HUVE to $19.5 \%$ when the HUVE was activated with IL- $1 \alpha$. Although this migration was less than the normal control used that same day, this could only be performed once because of the availability of patient blood. The migration of the LAD monocytes was completely blocked by mAb HP1/2 to $\alpha_{4}$ and nearly completely by mAb13 to $\beta_{1}$ integrin, confirming that VLA-4 $\left(\alpha_{4} \beta_{1}\right)$ is required for these CD11/CD18-deficient monocytes to migrate. The migration of
MAb

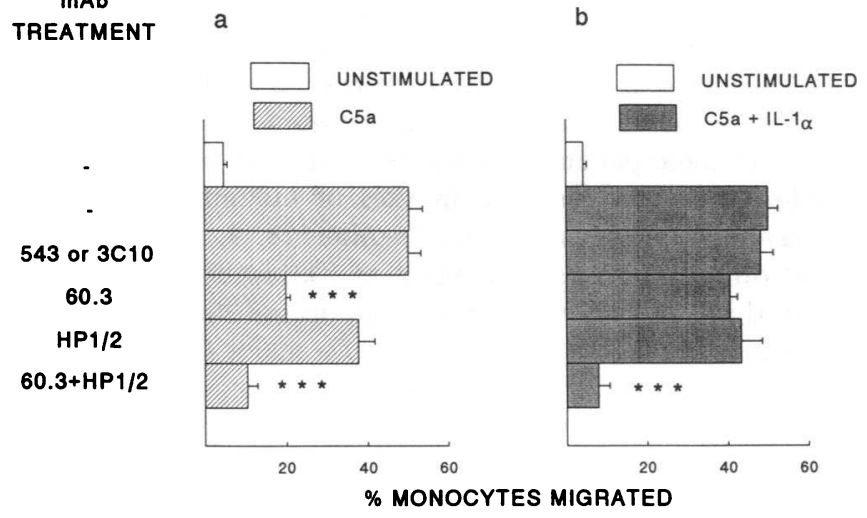

Figure 8. The effect of antibody to VLA-4 on C5a-induced monocyte migration across unactivated or IL- $1 \alpha$-activated endothelium. Labeled monocytes were incubated with saturating amounts of $\mathrm{mAb}$ 60.3 to CD18 and/or HP1/2 to $\alpha_{4}$ integrin of VLA-4 for $20 \mathrm{~min}$ at room temperature, and then added above unactivated HUVE $(a)$, or HUVE activated with IL-1 $\alpha(0.1 \mathrm{ng} / \mathrm{ml}$, for $5 \mathrm{~h})(b)$. Migration was in response to $\mathrm{C} 5 \mathrm{a}\left(5 \times 10^{-10} \mathrm{M}\right)$ added to the lower compartment. Data are expressed as the percent of added monocytes migrated and represent the mean \pm SEM of six separate experiments performed with triplicates. ${ }^{* * *} P<0.001$ compared with $(a)$ C5a- or $(b)$ C5a + IL-1treated group, using post hoc Bonferroni analysis.

the CD18-deficient monocytes was not inhibited by addition of $\mathrm{mAb}$ to $\mathrm{CD} 18$ (60.3) under any of the migration conditions tested (Table I).

\section{Discussion}

Under most conditions examined in vitro and in vivo, the leukocyte $\mathrm{CD} 11 / \mathrm{CD} 18$ or $\beta_{2}$ integrin complex is required for PMNL and monocyte migration. This is supported by the finding that $\mathrm{mAb}$ against the common $\beta$ chain (CD18) inhibits the

Table I. Migration of Leukocyte Adhesion (CD18) Deficiency Patients Monocytes through Endothelium

\begin{tabular}{|c|c|c|c|c|}
\hline \multicolumn{3}{|c|}{ Treatment* } & \multicolumn{2}{|c|}{ Percent of monocytes migrated } \\
\hline HUVE & $\mathrm{mAb}$ & C5a & Normal & LAD patient \\
\hline Unactivated & - & - & $2.3 \pm 1.2$ & $0.9 \pm 0.1$ \\
\hline Unactivated & - & + & $41.5 \pm 1.3$ & $5.9 \pm 0.5$ \\
\hline Unactivated & 60.3 & + & $8.9 \pm 0.5$ & $6.3 \pm 0.3$ \\
\hline Unactivated & HP1/2 & + & $41.6 \pm 0.8$ & $2.0 \pm 0.2$ \\
\hline Unactivated & Abl3 & + & $40.3 \pm 1.3$ & $4.5 \pm 0.4$ \\
\hline IL- $1 \alpha$ & - & - & $6.5 \pm 0.8$ & $9.8 \pm 2.7$ \\
\hline IL-1 $\alpha$ & - & + & $40.5 \pm 1.7$ & $19.5 \pm 3.0$ \\
\hline IL-1 $\alpha$ & 60.3 & + & $38.5 \pm 1.0$ & $25.9 \pm 3.7$ \\
\hline IL-1 $\alpha$ & HP1/2 & + & $43.0 \pm 1.6$ & $1.1 \pm 0.1$ \\
\hline IL-1 $\alpha$ & Ab13 & + & $46.1 \pm 0.4$ & $4.5 \pm 0.4$ \\
\hline
\end{tabular}

* HUVE were activated with IL-1 $\alpha(0.1 \mathrm{ng} / \mathrm{ml}, 5 \mathrm{~h})$ as indicated and monocytes were treated with mAb 60.3 (anti-CD18), HP1/2 (anti- $\alpha 4$ integrin) or Ab13 (anti- $\beta 1$ integrin) for $20 \mathrm{~min}$ before addition for migration as in Fig. $6 b$. Migration was induced with C5a $\left(5 \times 10^{-10}\right.$ M). ${ }^{\ddagger}$ Values are means of triplicate wells \pm SD. 
in vitro migration of monocytes and PMNLs and that PMNLs and monocytes of LAD patients, whose cells lack the CD11/ CD18 complex, are defective in migration to chemotactic factors or across IL-1-activated endothelium $(3,6-9,13)$. However, in these patients, monocytes, lymphocytes, and eosinophils have been observed in sites of inflammation and in delayed type hypersensitivity reactions $(8,9,17)$, suggesting that other molecules in addition to CD11/CD18 may be involved in the transendothelial migration of these leukocytes. Our results confirm the existence of a major CD18-independent mechanism utilized by monocytes for transendothelial migration which, to our knowledge is demonstrated for the first time with an in vitro system. This mechanism requires VLA-4 on the monocyte and is most active when the endothelium is activated by IL- 1 , TNF- $\alpha$, or LPS, and monocyte migration is potentiated by a chemotactic factor such as C5a or $\mathrm{N}$-formyl peptides (see text).

Exposure of HUVE to IL-1 or TNF- $\alpha$ is known to induce PMNL adhesion and migration $(3,6,12-14)$. These cytokines also increase monocyte adhesion and migration, although the migration response across activated HUVE is much weaker than with PMNL $(21-24,28)$. This monocyte behavior in vitro contrasts with in vivo findings, which show a strong monocyte recruitment to sites injected with these agents $(3,29-31)$. The weak in vitro monocyte migration across IL-1 or TNF- $\alpha-$ activated endothelium was considered by Hakkert et al. (28) to be related to the type of subendothelial matrix used for the HUVE. However, even with attempts by these authors to optimize this component, monocyte migration across IL-1-treated HUVE was much less than for PMNL (28). In the system described here, we examined the effect of different types of matrix (data not shown), but observed no significant effect on the relatively low monocyte migration shown in Fig. 2, across IL-1-activated HUVE.

Another factor we considered to be contributing to the monocyte migration observed in vivo is the generation of chemotactic factors since in sites of inflammation (e.g., synovial fluid and lung), these direct monocyte acting factors and endothelial activating cytokines such as IL-1 and TNF- $\alpha$ can be present simultaneously $(2,3,32-35)$. Furthermore, the vascular endothelium in inflamed tissues has been found to be "activated" with expression of leukocyte adhesion molecules (29, 37). Therefore, in this study, monocyte migration in response to chemotactic factors across unactivated and cytokine activated endothelium was investigated to simulate this in vivo situation. The migration induced by $\mathrm{C} 5 \mathrm{a}$ was rapid and strong (Fig. 1), irrespective of whether or not the endothelium was activated (Figs. 3 and 8). This migration across unactivated HUVE was largely CD18 dependent, since three different mAbs against CD18-inhibited monocyte migration by $70-75 \%$ in response to C5a (Figs. 3 and 4) or FNLP (not shown). However, migration induced by these chemotactic factors across IL-1-, TNF- $\alpha$-, or LPS-activated HUVE was completely CD18 independent because these same mAbs failed to inhibit migration at all under these conditions (Figs. 3 and 4 and text). The same results were obtained when the U937 cell line-derived monocyte-like cells were tested for migration under the same conditions (Fig. 5). This suggests that the CD18-independent migration observed is not the result of the purification process used to obtain blood monocytes, but rather, a property of monocyte lineage cells.
It is well known that on IL-1-, TNF- $\alpha$-, or LPS-pretreated endothelium adhesion molecules such as E-selectin, ICAM-1, and VCAM-1 are upregulated, increasing the adhesiveness for PMNLs and monocytes $(3,17,18)$. In this study, we show that the CD18-independent migration mechanism is enhanced by IL- $1 \alpha$, TNF- $\alpha$, or LPS pretreatment of HUVE, but not by IFN$\tau$ (Fig. 2). This is of interest because IFN- $\tau$ does not induce E-selectin or VCAM-1 on HUVE, although it does enhance expression of ICAM-1 $(3,16,17,21)$. This observation suggests ICAM-1 upregulation is not sufficient to mediate CD18-independent monocyte migration.

The role of E-selectin in monocyte and U937 cell binding has been previously studied. Although E-selectin appears to play a role in monocyte adhesion $(21,22,24)$, it is not required in the CD18-independent migration observed here, since the adhesion blocking mAb BB11 against E-selectin (46) had no effect on migration alone (not shown) or in combination with mAbs against ICAM-1 (Fig. $6 a$ ). Also L-selectin, which appears to be important for monocyte adhesion under shear force conditions (23), was not required for the migration we observed (Fig. $6 \mathrm{~b}$ ). However, our results show that the treatment of the activated HUVE with mAbs $2 \mathrm{G7}$ (or 4B9, not shown), which block VCAM-1-mediated adhesion to VLA-4 $(16,44)$, or the treatment of the monocytes with mAb HP1/2 to $\alpha_{4}$, which blocks the adhesion function of VLA-4 (42), essentially abolished the CD18-independent monocyte migration to C5a across IL-1-activated HUVE (Fig. $6 b$ ). This finding, combined with the fact that $\mathrm{mAb13}$, which reacts with $\beta_{1}$ integrin chain and blocks adhesion functions of $\beta_{1}$ integrins (43), was essentially as effective for inhibition as mAb HP1/2, strongly suggests that interaction between VCAM-1 on the HUVE and VLA-4 $\left(\alpha_{4} \beta_{1}\right)$ on the monocyte mediate CD18-independent migration across IL-1-activated HUVE. The importance of the $\alpha_{4}$ subunit, and specifically of the $\alpha_{4}$ cytoplasmic domain of VLA-4 for cell migration, has recently been elegantly shown using chimeric $\alpha_{2}, \alpha_{4}$, and $\alpha_{5}$ chains in transfected rhabdomyosarcoma cells (55). These findings are in agreement with our recent observations, that mAb to another $\beta_{1}$ integrin $\alpha$ chain, namely to $\alpha_{5}$ (mAb 16) does not inhibit monocyte CD18-independent migration (data not shown).

It is important to point out that in the presence of $\mathrm{mAb}$ to CD18, mAbs HP1/2 and Ab1 3 were able to inhibit monocyte migration almost until basal levels across both unactivated and IL-1-activated HUVE, while mAbs $2 \mathrm{G} 7$ or 4B9 against VCAM-1 decreased only the IL-1-enhanced CD18-independent migration and the anti-VCAM-1 mAbs were less effective than the anti- $\alpha_{4} \mathrm{mAb}(\mathrm{HP} 1 / 2)$ (Fig. 6, 7). These results do not appear to be caused by limiting amounts of mAbs because addition of four times higher concentrations of $\mathrm{mAb}$ to $\mathrm{CD} 18$ or to VCAM-1 gave the same results (data not shown). There may be several reasons for the more potent inhibition by $\mathrm{mAb}$ to $\alpha_{4}$ or $\beta_{1}$ than by mAbs to VCAM-1: (a) VLA-4 can bind not only to VCAM-1, but also to CS-1 fragment of fibronectin, a ligand present also on unactivated HUVE and mAb HP 1/2 blocks VLA-4 binding to both $(42,56) ;(b)$ the mAbs used to block VCAM-1 on the activated HUVE bind to domain 1 on VCAM-1, while VLA-4 binds to more than one domain (5759); and (c) another molecule present on activated and unactivated HUVE may also serve as a ligand for VLA-4. Currently, we are studying the second possibility by using mAbs against different domains of VCAM-1 (kindly provided by Dr. R. 
Lobb). Preliminary results show that both domains 1 and 4 need to be blocked simultaneously to observe complete inhibition of CD18-independent monocyte migration. Thus, this suggests that VCAM-1 on the endothelium may be the only ligand for mediating the VLA-4-dependent migration observed here. Further studies are ongoing to confirm these results. The results with monocytes from a patient with LAD, congenitally deficient in CD11/CD18 (homozygous) (< $4 \%$ of normal) (47) would appear to rule out the possibility that the mAbs to CD18 were not sufficient to block all CD11/CD18-dependent migration, since the LAD monocytes also migrated well across IL-1-activated HUVE, and to a lesser extent, across unactivated HUVE in response to C5a (Table I). These LAD monocytes also appeared to utilize VLA-4 as an alternative migration mechanism because mAb to $\alpha_{4^{-}}$or $\beta_{1}$-inhibited migration, while mAbs to CD18 had no effect on the migration of these monocytes (Table I).

On IL-1-activated HUVE, neither CD11/CD18 nor VLA4 alone appear to be required for migration to chemotactic factors such as C5a because blocking either of these integrins alone did not inhibit the migration response (Fig. $8 \mathrm{~b}$ ). Thus, one mechanism may substitute for the other on monocytes, and both mechanisms must be blocked to abolish monocyte migration across activated endothelium. In contrast, migration across unactivated endothelium in response to chemotactic factor is much more CD11/CD18 dependent (Fig. $8 a$ ), and VLA-4 functions as a less efficient alternative mechanism, perhaps because unactivated endothelium expresses fewer or lower affinity ligands for VLA-4 on the monocytes.

In addition to monocytes, lymphocytes, eosinophils, and basophils express VLA-4 (56). Neutrophils lack this integrin. The VLA-4 on basophils, eosinophils, and T lymphocytes has been shown by a number of studies to contribute to the adhesion of these leukocytes to cytokine-activated endothelium (58, 60,61 ). This adhesive function of VLA-4 involves, at least in part, VCAM-1 on the endothelium. However, most of the in vitro studies of the mechanism involved in the migration of $\mathrm{T}$ lymphocytes or eosinophils across IL-1-activated endothelium have identified a predominant role for CD11/CD18, with only a minor or insignificant contribution of VLA-4 or its ligand, VCAM-1, to the migration process $(62,63)$. This conclusion was also reached for $\mathrm{T}$ lymphocyte transendothelial migration in response to lymphocyte chemotactic factors (64). However, our finding that VLA-4 in monocytes can play a major role, in addition to CD11/CD18, in mediating cell migration is in agreement with a recent report that VLA-4 functions as a major mechanism by which eosinophils migrate across HUVE activated by IL-4 (but not IL-1) (65). In addition to these in vitro observations, there are now an increasing number of in vivo studies that implicate VLA-4 as an important integrin in T lymphocyte migration in the rat to dermal inflammatory reactions (e.g., delayed type hypersensitivity, TNF- $\alpha$ ) (66), or to the central nervous system in experimental allergic encephalitis (67). In this species, monocyte infiltration into the lung in IgA immune complex alveolitis (68) appears to also involve a VLA4-mediated mechanism.

Thus, the in vitro observations reported here demonstrating a major role on monocytes for VLA-4, and of one of its major ligands, VCAM-1 in transendothelial migration, is in accord with the increasing evidence of an important role for VLA-4 in leukocyte migration in vivo. Further studies in vitro should allow analysis at the molecule level of the contribution to monocyte migration of ligands for VLA-4 in addition to VCAM-1, the role of VLA-4, CD11/CD18, and its subtypes (LFA-1, MAC-1, and gp150/95) in migration during various monocyte and endothelial cell activation conditions, and potentially lead to developing strategies for regulating monocyte migration in pathological conditions.

\section{Acknowledgments}

The authors are grateful for gifts of important reagents from Drs. $R$. Rothlein, J. M. Harlan, W. Newman, T. Springer, C. W. Smith, K. Yamada, R. Lobb, D. Urdal, and from Genentech Inc. and CIBAGeigy Corp. We are also indebted to Dr. Z. Chad (Hôpital Ste. Justin, Montreal, PQ) for providing us blood from his patient with LAD disease and to Mrs. N. Lopes for her outstanding technical support throughout this study. The contribution of Dr. T. B. Issekutz to helpful discussions and assistance with flow cytometry analysis, and the excellent secretarial work of Ms. M. Hopkins and assistance with graphics by Mr. K. MacLeod are gratefully acknowledged.

This work was supported by an Izaak Walton Killam Children's Hospital research project award to H. E. Chuluyan and by grant MA7684 from the Medical Research Council of Canada held by A. C. Issekutz. H. E. Chuluyan was supported by an Izaak Walton Killam Children's Hospital Research Fellowship and currently is the recipient of a Dalhousie Medical Research Fellowship.

\section{References}

1. Movat, H. Z., and M. I. Cybulsky. 1987. Neutrophil emigration and microvascular injury. Role of chemotaxins, endotoxin, interleukin-1 and tumour necrosis factor $\alpha$. Surv. Synth. Pathol. Res. 6:153-176.

2. Goldstein, I. M. 1988. Complement: biologically active products. In Inflammation. Basic Principles and Clinical Correlates. J. I. Gallin, I. M. Goldstein, and R. Snyderman, editors. Raven Press, Ltd. New York. pp. 55-74.

3. Pober, J. S., and R. S. Cotran. 1990. Cytokines and endothelial cell biology. Physiol. Rev. 70:427-452.

4. Snyderman, R., and R. J. Uhing. 1988. Phagocytic cells: stimulus-response coupling mechanisms. In Inflammation. Basic Principles and Clinical Correlates. J. I. Gallin, I. M. Goldstein, and R. Snyderman, editors. Raven Press, Ltd., New York. pp. 309-324.

5. Buettner, H. M., D. A. Lauffenburger, and S. H. Zigmond. 1989. Measurement of leukocyte motility and chemotaxis parameters with the Millipore filter assay. J. Immunol. Methods. 123:25-37.

6. Smith, C. W., S. D. Marlin, R. Rothlein, C. Toman, and D. C. Anderson. 1989. Cooperative interactions of LFA-1 and Mac-1 with intercellular adhesion molecule- 1 in facilitating adherence and transendothelial migration of human neutrophils in vitro. J. Clin. Invest. 83:2008-2017.

7. Furie, M. B., M. C. A. Tancinco, and C. W. Smith. 1991. Monoclonal antibodies to leukocyte integrins $\mathrm{CD} 11 \mathrm{a} / \mathrm{CD} 18$ and $\mathrm{CD} 1 \mathrm{~b} / \mathrm{CD} 18$ or intercellular adhesion molecule-1 inhibit chemoattractant-stimulated neutrophil transendothelial migration in vitro. Blood. 78:2089-2097.

8. Fischer, A., B. Lisowska-Grospierre, D. C. Anderson, and T. A. Springer 1988. Leukocyte adhesion deficiency: molecular basis and functional consequences. Immunodefic. Rev. 1:39-54.

9. Anderson, D. C., M. Finegold, J. R. Rothlein, F. C. Schmalsteig, B. J. Hughes, L. J. Miller, S. Kohl, M. F. Tosi, R. L. Jacobs, T. C. Waldrop, et al. 1985. The severe and moderate phenotypes of heritable Mac-1, LFA-1 deficiency: their quantitative definition and relation to leukocyte dysfunction and clinical features. J. Infect. Dis. 152:668-689.

10. Muller, W. A., and S. A. Weigl. 1992. Monocyte-selective transendothelial migration: dissection of the binding and transmigration phases by an in vitro assay. J. Exp. Med. 176:819-828.

11. Keizer, G. D., A. A. Te Velde, R. Schwarting, C. G. Figdor, and J. E. De Vries. 1987. Role of p150,95 in adhesion, migration, chemotaxis, and phagocytosis of human monocytes. Eur. J. Immunol. 17:1317-1322.

12. Morzycki, W., J. Sadowska, and A. C. Issekutz. 1990. Interleukin-1 and tumour necrosis factor $\alpha$ induced polymorphonuclear leukocyte-endothelial cell 
adhesion and transendothelial migration in vitro: the effect of apical versus basal monolayer stimulation. Immunol. Lett. 25:331-340.

13. Luscinskas, F. W., M. I. Cybulsky, J.-M. Kiely, C. S. Peckins, V. M. Davis, and M. A. Gimbrone, Jr.. 1991. Cytokine-activated human endothelial monolayers support enhanced neutrophil transmigration via a mechanism involving both endothelial-leukocyte adhesion molecule-1 and intercellular adhesion molecule-1. J. Immunol. 146:1617-1625.

14. Moser, R, B. Schleiffenbaum, P. Groscurth, and J. Fehr. 1989. Interleukin 1 and tumor necrosis factor stimulate human vascular endothelial cells to promote transendothelial neutrophil passage. J. Clin. Invest. 83:444-455.

15. Bevilacqua, M. P., S. Stengelin, M. A. Gimbrone, Jr., and B. Seed. 1989. Endothelial leukocyte adhesion molecule 1: an inducible receptor for neutrophils related to complement regulatory proteins and lectins. Science. (Wash. DC). 243:1160-1165.

16. Carlos, T. M., B. R. Schwartz, N. L. Kovach, E. Yee, M. Rosso, L. Osborn, G. Chi-Rosso, B. Newman, R. Lobb, and J. M. Harlan. 1990. Vascular cell adhesion molecule-1 mediates lymphocyte adherence to cytokine-activated cultured human endothelial cells. Blood. 76:965-970.

17. Springer, T. A. 1990. Adhesion receptors of the immune system. Nature (Lond.). 346:425-434.

18. Lasky, L. A. 1992. Selectins: interpreters of cell-specific carbohydrate information during inflammation. Science (Wash. DC). 258:964-969.

19. Elices, M. J., L. Osborn, Y. Takada, C. Crouse, S. Luhowskyj, M. E. Hemler, and R. R. Lobb. 1990. VCAM-1 on activated endothelium interacts with the leukocyte integrin VLA-4 at a site distinct from the VLA-4/fibronectin binding site. Cell. 60:577-584.

20. Osborn, L., C. Hession, R. Tizard, C. Vassallo, S. Luhowskyj, G. ChiRosso, and R. Lobb. 1989. Direct expression cloning of vascular cell adhesion molecule 1 , a cytokine-induced endothelial protein that binds to lymphocytes. Cell. 59:1203-1211.

21. Carlos, T., N. Kovach, B. Schwartz, M. Rosa, B. Newman, E. Wayner, C Benjamin, L. Osborn, R. Lobb, and J. Harlan. 1991. Human monocytes bind to two cytokine-induced adhesive ligands on cultured human endothelial cells: endothelial-leukocyte adhesion molecule- 1 and vascular cell adhesion molecule-1 Blood. 77:2266-2271.

22. Jonjic, N., P. Jílek, S. Bernasconi, G. Peri, I. Martin-Padura, S. Cenzuales, E. Dejana, and A. Mantovani. 1992. Molecules involved in the adhesion and cytotoxicity of activated monocytes on endothelial cells. J. Immunol. 148:20802083.

23. Spertini, O., F. W. Luscinskas, M. A. Gimbrone, Jr., and T. F. Tedder. 1992. Monocyte attachment to activated human vascular endothelium in vitro is mediated by leukocyte adhesion molecule-1 (L-selectin) under nonstatic conditions. J. Exp. Med. 175:1789-1792.

24. Beekhuizen, H., A. J. Corsel-van Tilburg, I. Blokland, and R. van Furth. 1991. Characterization of the adherence of human monocytes to cytokine-stimulated human macrovascular endothelial cells. Immunology. 74:661-669.

25. Migliorisi, G., E. Folkes, N. Pawlowski, and E. B. Cramer. 1987. In vitro studies of human monocyte migration across endothelium in response to leukotriene $\mathrm{B}_{4}$ and f-Met-Leu-Phe. Am. J. Pathol. 127:157-167.

26. Verghese, M. W., and R. Snyderman. 1989. Chemotaxis and chemotactic factors. In Human monocytes. M. Zembala and G. L. Asherson, editors. Academic Press Limited, London. pp. 167-175.

27. Darby, H., K. A. Brown, R. A. Anderson, B. T. Williams, and D. C. Dumonde. 1988. Transendothelial chemotaxis in vitro of human monocytes. $J$ Immunol. Methods. 113:157-163.

28. Hakkert, B. C., T. W. Kuijpers, J. F. M. Leeuwenberg, J. A. Van Mourik, and D. Roos. 1991. Neutrophil and monocyte adherence to and migration across monolayers of cytokine-activated endothelial cells: the contribution of CD18, ELAM-1, and VLA-4. Blood. 78:2721-2726.

29. Ringler, D. J., D. G. Walsh, J. J. MacKey, R. P. McEver, R. D. Hunt, and W. Newman. 1992. Sequential cutaneous cytokine localization, leukocyte-endothelial cell adhesion molecule (CAM) expression, and leukocyte typing in rhesus monkeys receiving intradermal LPS. FASEB (Fed. Am. Soc. Exp. Biol.) J. 6:A1889.

30. Sáez-Llorens, X., H. S. Jafari, K. D. Olsen, H. Nariuchi, E. J. Hansen, and G. H. McCracken, Jr.. 1991. Induction of suppurative arthritis in rabbits by Haemophilus endotoxin, tumor necrosis factor- $\alpha$, and interleukin-1 $\beta$. J. Infect. Dis. 163:1267-1272.

31. Issekutz, A. C., and T. B. Issekutz. 1993. Quantitation and kinetics of blood monocyte migration to acute inflammatory reactions and IL- $1 \alpha$, tumor necrosis factor- $\alpha$, and IFN- $\tau$. J. Immunol. 151:1-11.

32. Oppenheim, J. J., C. O. C. Zachariae, N. Mukaida, and K. Matsushima 1991. Properties of the novel proinflammatory supergene "intercrine" cytokine family. Annu. Rev. Immunol. 9:617-648.

33. Yoshimura, T., and E. J. Leonard. 1992. Human monocyte chemoattractant protein-1: structure and function. Cytokines. 4:131-152.

34. Firestein, G. S. 1992. Cytokines in autoimmune diseases. Concepts Immunopathol. 8:129-160.
35. Jones, M. L., and J. S. Warren. 1992. Monocyte chemoattractant protein 1 in a rat model of pulmonary granulomatosis. Lab. Invest. 66:498-503.

36. Koch, A. E., J. C. Burrows, G. K. Haines, T. M. Carlos, J. M. Harlan and S. J. Leibovich. 1991. Immunolocalization of endothelial and leukocyte adhesion molecules in human rheumatoid and osteoarthritic synovial tissues. Lab. Invest. 64:313-320.

37. Pober, J. S., and R. S. Cotran. 1991. What can be learned from the expression of endothelial adhesion molecules in tissues. Lab. Invest. 64:301-305.

38. Beatty, P. G., J. A. Ledbetter, P. J. Martin, T. H. Price, and J. A. Hansen 1983. Definition of a common leukocyte cell-surface antigen (GP95-150) associated with diverse cell-mediated immune functions. J. Immunol. 131:29132919.

39. Argenbright, L. W., L. G. Letts, and R. Rothlein. 1991. Monoclonal antibodies to the leukocyte membrane CD18 glycoprotein complex and to intercellular adhesion molecule-1 (ICAM-1) inhibit leukocyte-endothelial adhesion in rabbits. J. Leukocyte Biol. 49:253-257.

40. Diamond, M. S., D. E. Staunton, S. D. Marlin, and T. A. Springer. 1991. Binding of the integrin Mac-1 (CD11b/CD18) to the third immunoglobulin-like domain of ICAM-1 (CD54) and its regulation by glycosylation. Cell. 65:961-971.

41. Kishimoto, T. K., M. A. Jutila, and E. C. Butcher. 1990. Identification of a human peripheral lymph node homing receptor: a rapidly down-regulated adhesion molecule. Proc. Natl. Acad. Sci. USA. 87:2244-2248.

42. Pulido, R., M. J. Elices, M. R. Campanero, L. Osborn, S. Schiffer, A García-Pardo, R. Lobb, M. E. Hemler, and F. Sánchez-Madrid. 1991. Functiona evidence for three distinct and independently inhibitable adhesion activities mediated by the human integrin VLA-4. Correlation with distinct $\alpha_{4}$ epitopes. $J$. Biol. Chem. 266:10241-10245.

43. Akiyama, S. K., S. S. Yamada, W. T. Chen, and K. M. Yamada. 1989. Analysis of fibronectin receptor function with monoclonal antibodies: roles in cell adhesion, migration, matrix assembly, and cytoskeletal organization. J. Cell. Biol. 109:863-875.

44. Graber, N., T. V. Gopal, D. Wilson, L. D. Beall, T. Polte, and W. Newman. 1990. T cells bind to cytokine-activated endothelial cells via a novel, inducible sialoglycoprotein and endothelial leukocyte adhesion molecule-1. J. Immunol. 145:819-830.

45. Makgoba, M. W., M. E. Sanders, G. E. Luce, M. Dustin, T. A. Springer, E. A. Clark, P. Mannoni, and S. Shaw. 1988. ICAM-1, a ligand for LFA-1-dependent adhesion of B, T and myeloid cells. Nature (Lond.). 331:86-90.

46. Benjamin, C., I. Dougas, G. Chi-Rosso, S. Luhowskyj, M. Rosa, B. Newman, L. Osborn, C. Vassallo, C. Hession, S. Goelz, K. McCarthy, and R. Lobb. 1990. A blocking monoclonal antibody to endothelial-leukocyte adhesion molecule-1 (ELAM1). Biochem. Biophys. Res. Commun. 171:348-353.

47. Wright, S. D., P. A. Detmers, Y. Aida, R. Adamowski, D. C. Anderson, Z Chad, L. G. Kabbash, and M. J. Pabst. 1990. CD18-deficient cells respond to lipopolysaccharide in vitro. J. Immunol. 144:2566-2571.

48. Boyum, A. 1983. Isolation of human blood monocytes with Nycodenz, a new non-ionic iodinated gradient medium. Scand. J. Immunol. 17:429-436.

49. Recalde, H. R. 1984. A simple method of obtaining monocytes in suspension. J. Immunol. Methods. 69:71-77.

50. Metcalf, J. A., J. I. Gallin, W. M. Nauseef, and R. K. Root. 1986. Preparation of cells and materials for functional assays. In Laboratory Manual of Neutrophil Function. Raven Press, Ltd., New York. pp. 2-29.

51. Gavison, R., Y. Matzner, and E. Fibach. 1988. Differential induction of monocytic functions by dibutyryl cyclic AMP and retinoic acid in human monoblast cell line U937. Isr. J. Med. Sci. 24:697-701.

52. Jaffe, E. A., R. L. Nachman, C. G. Becker, and C. R. Minick. 1973. Culture of human endothelial cells derived from umbilical veins. Identification by morphological and immunologic criteria. J. Clin. Invest. 52:2745-2752.

53. Issekutz, A., and N. Lopes. 1993. Endotoxin activation of endothelium for polymorphonuclear leukocyte transendothelial migration and modulation by interferon $\tau$. Immunology. 79:600-607.

54. Fernandez, H. N., P. M. Henson, A. Otani, and T. Hugli. 1978. Chemotactic responses to human $\mathrm{C} 3 \mathrm{a}$ and $\mathrm{C5a}$ anaphylatoxins $\mathrm{I}$. Evaluation of $\mathrm{C} 3 \mathrm{a}$ and C5a leukotaxis in vitro and under simulated in vivo conditions. J. Immunol. 120:109-115.

55. Chan, B. M., P. D. Kassner, J. A. Schiro, H. R. Byers, T. S. Kupper, and M. E. Hemler. 1992. Distinct cellular functions mediated by different VLA integrin $\alpha$ subunit cytoplasmic domains. Cell. 68:1051-1060.

56. Hemler, M. E. 1990. VLA proteins in the integrin family: structures, functions, and their role on leukocytes. Annu. Rev. Immunol. 8:365-400.

57. Pepinsky, B., C. Hession, L.-L. Chen, P. Moy, L. Burkly, A. Jakubowski, E. P. Chow, C. Benjamin, G. Chi-Rosso, S. Luhowskyj, and R. Lobb. 1992 Structure/function studies on vascular cell adhesion molecule-1. J. Biol. Chem. 267:17820-17826

58. Vonderheide, R. H., and T. A. Springer. 1992. Lymphocyte adhesion through very late antigen 4 : evidence for a novel binding site in the alternatively 
spliced domain of vascular cell adhesion molecule 1 and an additional $\alpha_{4}$ integrin counter-receptor on stimulated endothelium. J. Exp. Med. 175:1433-1442.

59. Osborn, L., C. Vassallo, and C. D. Benjamin. 1992. Activated endothelium binds lymphocytes through a novel binding site in the alternately spliced domain of vascular cell adhesion molecule-1. J. Exp. Med. 176:99-107.

60. Bochner, B. S., F. W. Luscinskas, M. A. Gimbrone, Jr., W. Newman, S. A. Sterbinsky, C. P. Derse-Anthony, D. Klunk, and R. P. Schleimer. 1991. Adhesion of human basophils, eosinophils, and neutrophils to interleukin 1-activated human vascular endothelial cells: contributions of endothelial cell adhesion molecules. J. Exp. Med. 173:1553-1556.

61. Oppenheimer-Marks, N., L. S. Davis, D. T. Bogue, J. Ramberg, and P. E. Lipsky. 1991. Differential utilization of ICAM-1 and VCAM-1 during the adhe sion and transendothelial migration of human T lymphocytes. J. Immunol. 147:2913-2921.

62. Oppenheimer-Marks, N., L. S. Davis, and P. E. Lipsky. 1990. Human T lymphocyte adhesion to endothelial cells and transendothelial migration: alteration of receptor use relates to the activation status of both the $\mathrm{T}$ cell and the endothelial cell. J. Immunol. 145:140-148.
63. Moser, R., J. Fehr, L. Olgiati and P. L. B. Bruijnzeel. 1992. Migration of primed human eosinophils across cytokine-activated endothelial cell monolayers. Blood. 79:2937-2945.

64. Van Epps, D. E., J. Potter, M. Vachula, C. W. Smith and D. C. Anderson 1989. Suppression of human lymphocyte chemotaxis and transendothelial migration by LFA-1 antibody. J. Immunol. 143:3207-3210.

65. Moser, R., J. Fehr and P. L. B. Bruijnzeel. 1992. IL-4 controls the selective endothelium-driven transmigration of eosinophils from allergic individuals. $J$. Immunol. 149:1432-1438.

66. Issekutz, T. B., and A. Wykretowicz. 1991. Effect of a new monoclonal antibody, TA-2, that inhibits lymphocyte adherence to cytokine stimulated endothelium in the rat. J. Immunol. 147:109-116.

67. Yednock, T. A., C. Cannon, L. C. Fritz, F. Sanchez-Madrid, L. Steinman and N. Karin. 1992. Prevention of experimental autoimmune encephalomyelitis by antibodies against $\alpha_{4} \beta_{1}$ integrin. Nature (Lond.). 356:63-66.

68. Mulligan, M. S., G. S. Wilson, R. F. Todd, C. W. Smith, D. C. Anderson, J. Varani, T. B. Issekutz, M. Miyasaka, T. Tamatani, J. Rusche, et al. 1993. Role of $\beta_{1}, \beta_{2}$ integrins and ICAM-1 in lung injury after deposition of IgG and IgA immune complexes. J. Immunol. 150:2407-2417. 